\title{
How to Improve Collaboration Efficiency in the Built Environment of Factories by Using an Integrated Factory Modelling Concept - An Expert Study
}

\author{
Peter Burggräf, Matthias Dannapfel, Matthias Ebade Esfahani*, Nora Schwamborn \\ Laboratory for Machine Tools and Production Engineering (WZL) of RWTH Aachen University, Aachen 52074, Germany
}

Corresponding Author Email: m.ebade-esfahani@wzl.rwth-aachen.de

https://doi.org/10.18280/ijdne.150403

Received: 8 February 2020

Accepted: 30 June 2020

\section{Keywords:}

BIM, collaboration, design, expert study, factory, factory design, design

\begin{abstract}
Factory design involves the design of a complex production system in coherence with the requirements of the surrounding building envelope. These two disciplines, however, are still not integrated in order to be able to perform a completely BIM-based factory design that can be used to minimise design-related delays and reduce the cost of a factory design project. Main obstacles are unaligned levels of development, lack of transparency of informational relations and inefficient collaboration between production design and $\mathrm{MEP}(\mathrm{H})$ design. The objective of this paper is hence the generation and discussion of two concrete solution recommendations through an explorative expert study to overcome the already identified obstacles hindering an efficient BIM-based factory design process.
\end{abstract}

\section{INTRODUCTION}

In many countries, BIM is already part of many construction projects. But in today's practice of the German construction sector, planning and designing with BIM has not been established as the standard procedure, leaving the productivity in the construction sector at a comparably low level of growth (as shown in Figure 1) [1].

To this end, Germany has launched several initiatives as for example "planen-bauen 4.0". Its tasks are the design, coordination and support of the BIM-based digitisation of the entire value chain of the German built environment [3].

The construction sector involves a comparably high amount of small companies in each project, each with expertise in a niche area [4]. It can be divided into different sectors, e.g. private housing, public construction or industrial construction. Within industrial construction, factory design is a special area. Nevertheless, the stagnation of productivity in the whole construction sector shown in Figure 1 also applies to factory design.

A typical factory design project is depicted schematically in Figure 2. Factory design can be seen as the coherent design of two inseparable systems: the inner value-adding core - so production and logistics - and the surrounding building shell - so, for instance, architecture or structural engineering. The design of both systems takes place in parallel. The upper part of the figure shows the work phases according to the "Fee Scale for Architects and Engineers" (HOAI) determining the process of building designers [5]. In the lower part of the figure, the process flow of production design is divided into its usual seven phases [6]. Information must be continuously exchanged between the design of the building and the design of the production system. The various kinds of design information, exemplarily illustrated on the left side of Figure 2 , range from layout designs to machine designs and drawings of piping systems. The figure indicates a separation between building design and production design. This is to say that despite the strong interdependencies of both design fields, the design process itself is mainly done in a pure milestoneoriented way with only little information exchange between the two fields.

This is where the general idea of BIM sets in, providing the opportunity of integrating the two parallel processes and ensuring that the exchange of design information between the designing disciplines as well as the exchange of information during subsequent maintenance activities is improved [7,8]. Such integration and improvement can lead to a minimisation of information losses and a reduction of costs resulting from design errors.

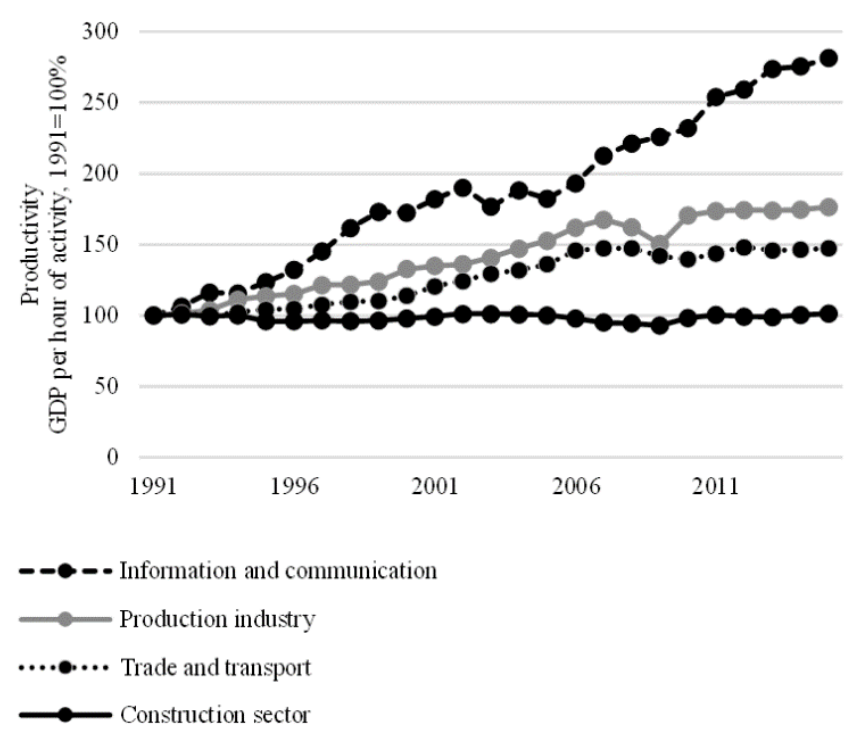

Figure 1. Productivity development in Germany by sectors 


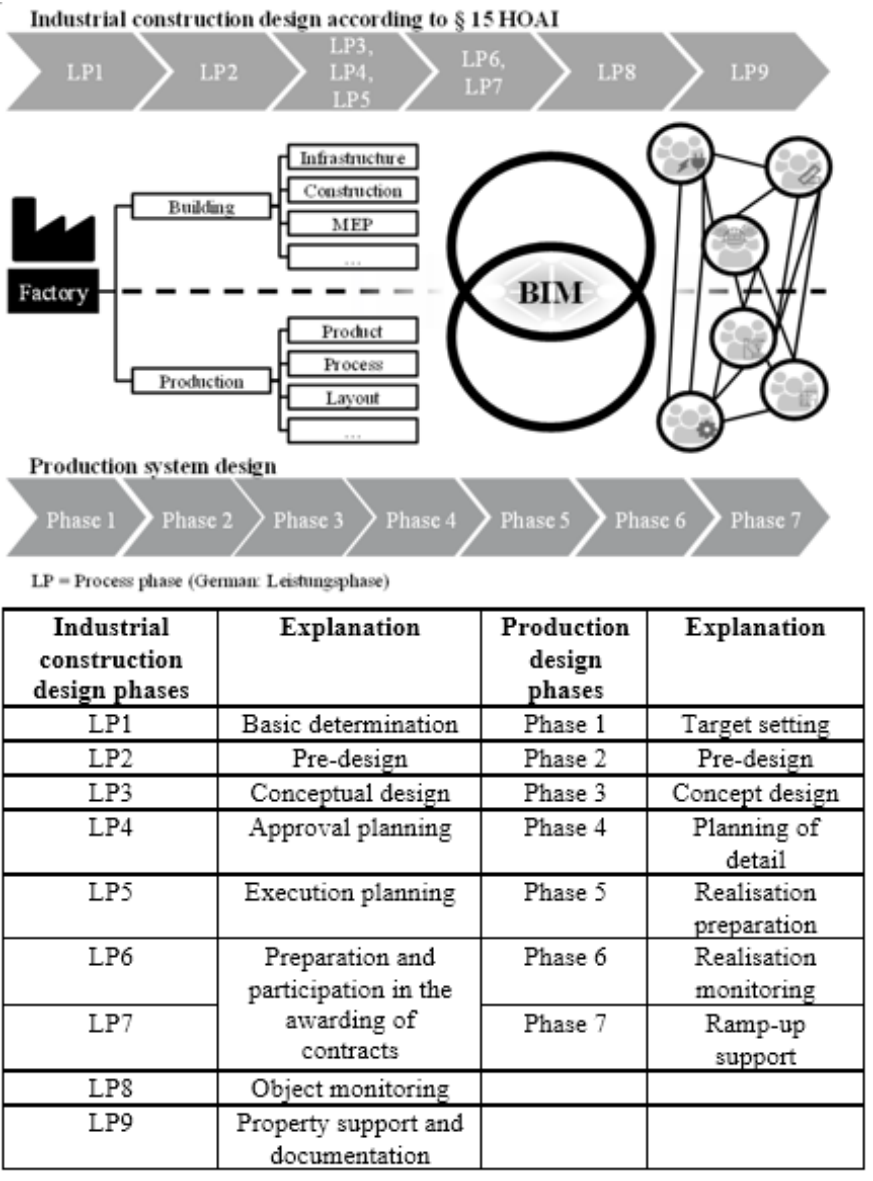

Figure 2. Factory design process [5, 6, 9]

However, even in factory design projects where BIM is used, the two systems are still not planned in a coherent way. Burggräf et al. [10] have contributed this phenomenon to three major obstacles:

(1) Inefficient collaboration within the cost-intensive design interface of $\operatorname{MEP}(\mathrm{H})$ (Mechanical, Electrical, Plumbing, Heating) and production/process

(2) Unaligned level of development between the different design disciplines in the factory design process

(3) Lack of transparency regarding the informational relation among the design tasks of different disciplines and the associated change effects

While there have been several research efforts to improve collaboration with BIM in recent years, these efforts have not yet comprehensively delivered solutions that integrate manufacturing systems.

Arayici et al. explored interoperability specifications in the design phase of a BIM design process with a strong focus on energy efficiency. Although a transfer to industrial construction was not explicitly excluded, the specifications are very much related to elements of the building shell (e.g. facades and wall openings) [11].

$\mathrm{Hu}$ et al. have developed a concept called "BIM-FIM" to integrate the phases of operation and maintenance of a building into a Building Information Model. They have emphasised the importance of digitalised BIM information for the life cycle management of a building. They explicitly have referred not only to geometrical information but also to semantic, non-geometrical information. The current problem prevalent in industry is described as the lack of such key information from $\operatorname{MEP}(\mathrm{H})$ components and their logical relationships to each other. The approach leaves out the design phase and focuses only on the building phases operation and maintenance. Furthermore, the relationship of $\operatorname{MEP}(H)$ to production-relevant issues has missed [12].

In a case study, Lee et al. explored a process for the transparent and interoperable creation of information for precast concrete elements. First of all, they investigated how documents can be created from an ontology that meet the standards of the international BIM organisation buildingSMART. These include in particular the Information Delivery Manual (IDM) and the Model View Definitions (MVD). The researchers then derived a rule level using the Semantic Web Rule Language (SWRL) to validate the information model. The process of transferring an ontology model into IDMs described here has been particularly relevant for the paper at hand. Due to the focus on precast concrete elements, however, the clear reference to questions of a production process in a factory is missing [13].

Ma et al. described how collaboration in the construction industry can be improved through Integrated Project Delivery (IPD), especially in the design phase of buildings. Missing representation of the relationships of the deliverables with each other (third functional requirement of the model according to Ma et al.) is one of the core problems in BIMbased factory design already described by Burggräf et al. [10], although $\mathrm{Ma}$ et al. did not describe their explanations on a parameter level. Furthermore, the researchers focused on the HVAC area (Heating, Ventilation, Air-Conditioning), but without referencing industrial construction or the consideration of BIM [14].

Current approaches have therefore not holistically met the requirements to optimise the BIM-based factory design process within the interface of $\operatorname{MEP}(\mathrm{H})$ and production/process. The connecting factors of those approaches for the study at hand, however, were the systematic integration of the research methodologies in the development of ontologies as well as derived checking logics based on existing BIM-standards of buildingSMART [15] (see section $3)$.

For this reason, this study aimed at the development of concrete solution recommendations to facilitate BIM-based factory design within the interface of $\operatorname{MEP}(\mathrm{H})$ and production/process, explicitly targeting the efficient validation of design deliveries. The concrete solution recommendations were developed by using expert interviews and conventional content analysis.

The remainder of the paper is structured as follows:

Section 2 describes the methodological procedure used during the interviews and in the subsequent evaluation of the information. Section 3 thereupon presents the concrete solution recommendations as results from the expert study. The last section provides a conclusion, an implementation and an outlook for future research activities based on the acquired results.

\section{RESEARCH METHODOLOGY}

Section 1 has shown that existing research efforts cannot holistically cover the obstacles within the current BIM-based factory design process. The results from our state of the art review, however, offered individual initial concepts for the study that formed the basis for the research process of the paper at hand [16]. The research objective has been formulated by extending the initial concepts by observations and 
experience from industry projects of the Laboratory for Machine Tools and Production Engineering WZL of RWTH Aachen University.

Due to the small number of suitable research projects mentioned in section 1 and given the highly interdisciplinary nature of the research topic, the authors have chosen an explorative approach in form of an expert study. This study should transform the initial concepts into concrete solution recommendations.

In order for the expert study to be substantiated, it is relevant to first explain our definition of the term 'expert': It is understood to represent a person with privileged access to relevant expertise, for example through practical experience [17]. Taking this definition into account, the panel of the study consisted of 11 experts from the fields of architecture, production design and $\mathrm{MEP}(\mathrm{H})$. To reduce systematic bias and to comply with the European GDPR (General Data Protection Regulation), anonymity was guaranteed to the participants, which is why the exact names of the companies and interviewees are not mentioned explicitly.

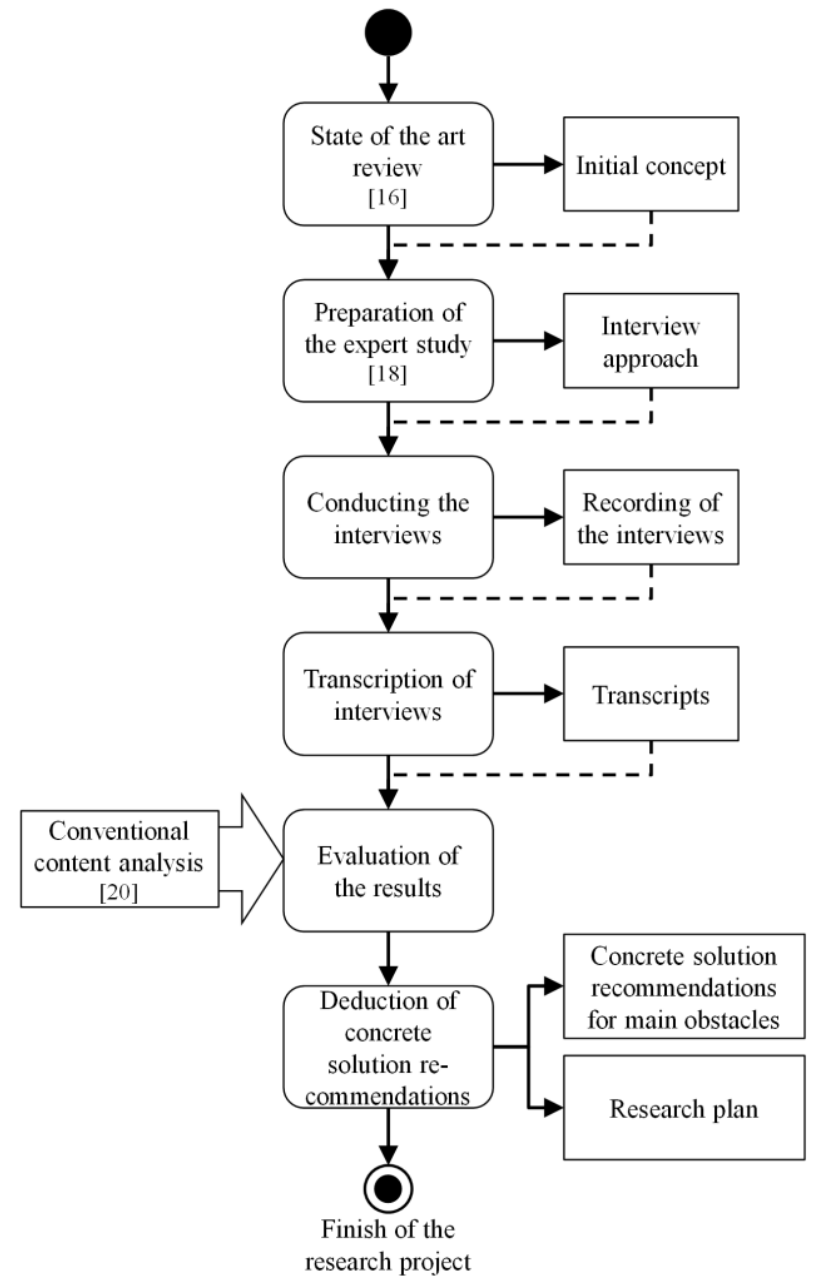

$\begin{array}{|ll|}\square & \text { Information } \\ \longrightarrow & \text { Activity } \\ \longrightarrow \rightarrow & \text { Tool } \\ \longrightarrow & \text { Process Flow } \\ \end{array}$

Figure 3. Flowchart of the solution-oriented expert study (K3-method [22])
In Figure 3, the entire process of data collection and the subsequent analysis of the generated data is shown: The initial concepts have formed the basis of the expert study. In the course of the interviews, these concepts were discussed, new requirements for target-oriented concepts were included and new processes and solution artefacts were developed together with the experts. Each interview was conducted according to an interview guideline previously prepared by the researcher [18]. Each of these partially standardised interviews lasted approximately 90 minutes and was performed in a one-on-one conversation either via telephone conference or via an inperson interview. After the automated transcription of the interviews, their content was analysed following the procedures described by Mayring [19] and Hsieh [20]: There are three variants of content analysis: conventional, directional and summative analysis. Directional analysis challenges already known theories and research results; summative analysis deals with counting and comparison of contents and keywords. Both were unsuitable for the topic dealt within this paper. However, the conventional approach, which is mainly used to describe partly unknown phenomena, was preferable given the exploratory nature of the performed study.

Following conventional content analysis, codes were derived from the interview transcripts by highlighting exact words that contribute to developing a solution for the identified obstacles [21]. Subsequently, based on additional notes, these codes were categorised into labels and categories. As a result of this content analysis, the core findings of the expert study were evaluated and further developed into two concrete solution recommendations. These results will be described in the next section.

\section{RESULTS}

In the following, the concrete solution recommendations as results of the expert study are presented, aiming to solve the obstacles investigated by Burggräf et al. [10].

\subsection{Using ontologies for automatic design validation}

The first concrete solution recommendation addresses the obstacles 1 and 3 from Burggräf et al. [10] (see section 1).

A desirable vision would be an automatic validation of deliveries from all design disciplines - especially those from $\mathrm{MEP}(\mathrm{H})$ and production design - without the need of human interference. The implementation of such a validation approach requires the integration of calculation-based validations. It has to be stressed that a simple check of the pure existence of a certain parameter is no longer sufficient since miscalculations can lead to costly consequences, as for example in terms of transformer or compressor design corrections. Up to now, only the following automatic validation have been made possible in BIM:

In today's practice, an automated geometrical collision check is performed routinely, so for example to see whether a pipe is clashing with a column.

In the field of non-geometrical information, however, the experts mentioned certain achievements, but these are either only applicable to a small niche of design operations or are not able to provide validations to the desired extent: For example, the Natural Language Processing (NLP) approach by ElGohary et al. is an automation of the Requirement, Applies, Select, and Exception (RASE) approach, which allows to 
automatically capture text segments from building regulations. However, its applicability is limited by the fact that the selfdevelopment of rules and the verification of design deliverables against these rules is not possible or only in a very inaccurate manner [23-25].

Solibri Office (formerly Solibri Model Checker), as another example, has been developed as an approach that verifies IFCbased models for geometrical collisions, missing semantic information and compliance with modelling agreements (e.g. whether the value range of the data is reasonable). The problem here is the use of a black-box method which is common for almost all commercial products with proprietary processes and file formats. The consequence is that rules cannot be transparently traced or changed, and new rules can only be added in a rather complicated way (in this case, by using the Solibri API) [26].

Visual programming languages (VPLs) are another example of how rules are constructed and used within BIM. Environments such as Grasshopper or Dynamo are good ways to simplify rule validation by creating rules intuitively (e.g. simple if-then rules) and referencing attributes from the model which the rules can then work on $[27,28]$. The major problem with VPLs up to now is that even though they are following a black-box method, the researcher is dependent on certain proprietary and commercial software in order to create the logic of the rules. It is our understanding that within research, the creation of the logic itself and also the subsequent implementation of the validation logic should be independent on specific commercial environments and rather be opensource accessible.

A Management Information System (MIS) is another approach that could be applicable in this regard as its most relevant task is to verify non-geometrical information. In BIMbased factory design, however, a coherent process is needed that includes both geometrical and non-geometrical information.

Considering the mentioned approaches, a different approach seemed preferable which has been tried out by Lee in a similar way (see section 1). In this approach, linked open data and ontologies are applied to express the logic behind the validation and to make the validation operable, too [13].

Ontologies are part of open-source knowledge engineering and thereby promoters of the Semantic Web. As a further development of the World Wide Web, the Semantic Web is a machine-interpretable network of information enabling the reuse of existing knowledge of ontologies. Ontologies are preferable when it comes to data integration ambiguities in terminologies among different design disciplines. Another advantageous characteristic of ontologies is their open-worldassumption which distinguishes them from, for instance, UML or other model-based system languages which are based on a closed-world-assumption. This characteristic express whether the lack of certain information is to be evaluated to be false (closed-world-assumption) or simply unknown (open-worldassumption) [29]. In BIM-based factory design, this is a crucial distinction given the high degree of unknown parameters at the beginning of the design process.

The ontology example in Figure 4 shows that, on the one hand, relationships between objects or classes can be represented transparently and, on the other hand, these very relationships themselves carry a meaning such as "consists of", "is Supplied By", "is Connected To" and "is Powered By".
The system represented in Figure 4 consists of Machine A and Machine B that is supplied by Machine A. Furthermore, the visualisation of the ontology shows that Machine A needs a connection to the Waste Water Pipe and is powered through a Power Supply Connection. Every class carries certain attributes [30] which again are connected to the class in form of Data Properties: has Position, has Type or has Port.

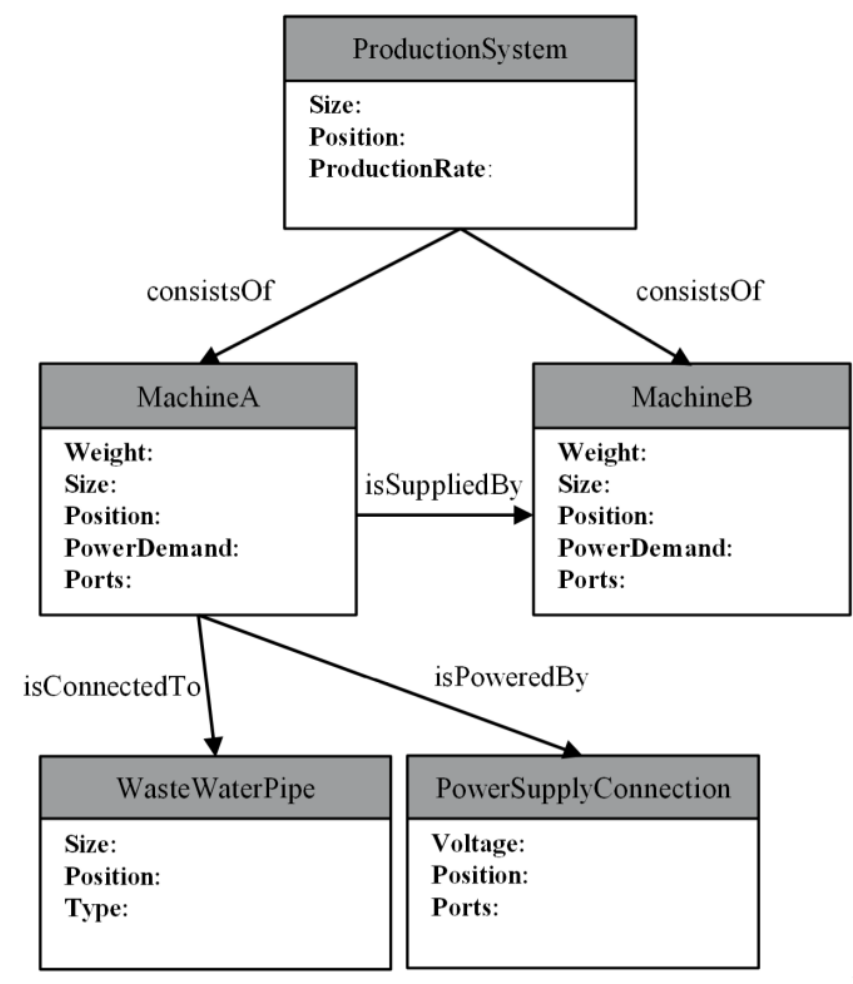

Figure 4. Ontology example

Using ontologies for automatic design information validation would yield various benefits. The already mentioned technical integrability of information from different design tools used by different design disciplines improves the timeliness, correctness, consistency and completeness of design data, and it fosters the prevention of data redundancy, too. In addition, just like in the Building Information Model, the information inside the ontology regarding the factory design process is structured in an objectoriented way.

The largest benefit, according to the experts, however, is the separation of the generally valid information model and the project-specific data storage. This means that an ontology as shown in Figure 4 can be established which is to be seen as generally applicable to all projects within this design interface because the connections between classes and attributes do not change for each project. For a specific project, you would then use the general information model and nurture it with projectspecific data, i.e. characteristics (e.g. numbers) of certain attributes. Subsequently, it would be possible to create rules and validation algorithms which check for the integrity of the project-specific ontology and for the adherence to projectspecific specifications and reference values.

In the very end, it is possible to lead the ontology logic back to an application in proprietary software as the ontology logic can be used for constructing software-specific code. 


\subsection{Factory design IDM and levels of development}

The concrete solution recommendation from our expert study addressing obstacle 2 from Burggräf et al. contains the development of documents and artefacts based on buildingSMART standards $[10,15]$.

The entire design process of factories is based on the crosswork interaction and collaboration of different design disciplines. A usual problem in German factory design processes is that the results of production design are expected to be delivered at an early stage of the project. Based on this information, for example, the $\operatorname{MEP}(\mathrm{H})$ designers carry out their calculations, designs and simulations. If, during the $\mathrm{MEP}(\mathrm{H})$ design process, the production requirements change without notifying the affected design disciplines such as $\operatorname{MEP}(\mathrm{H})$, their design result may be inconclusive.

Furthermore, as in all BIM design processes, the efficiency depends to a significant extent on the accuracy of the available data and information provided by other design disciplines [31]. As a consequence, the lack of access to required data or information is seen as a major obstacle. However, this does not necessarily mean a lack of authorisation or the delivery of data in a wrong file format, but rather refers to an appropriate Level of Development (LOD). In the context of the paper at hand, we have used the term Level of Development and the commonly used expression Level of Detail as synonyms. When evaluating the LOD, especially in the context of production equipment, it needs to be distinguished between the Level of Geometry (LOG) and the Level of Information (LOI). By the LOG, information about the fineness of detail of the graphical elements of a model is given. In contrast to this, the LOI is used to express the amount of non-geometrical information of the model. The required information (both LOG and LOI) depends on the requesting design discipline and the overall design progress. In factory design practice, however, LOG and LOI are often not provided with the amount of details that is needed by their recipients [10].

To solve this obstacle, the experts in our study proposed using the overall LOD framework of the BIMForum. The BIMForum has established LOD specifications for many objects that are used within BIM-construction projects. A further discussion with the experts revealed that those specifications, however, hardly consider objects of production equipment. Another drawback is that they strongly focus on the objects' LOG. The LOI, however, is dealt with on a much less granular level, or in other words: While it is explained that non-geometrical information must be delivered at a certain LOD stage, it is not clearly defined which data and values must be contained within that delivery [32]. Together with the experts, we developed Levels of Development (LODs) for factory design that suit both production design and $\operatorname{MEP}(\mathrm{H})$ design. Our development is based on using the overall 5-step LOD-framework of the BIMForum [32]. Additionally, the development was facilitated by considering the Aachen factory planning approach. This approach is already equipped with an information maturity model at a project management level. Although it lacks the refinement on a parameter level, the high-level organisation of information delivery priorities served well for our purpose $[33,34]$.

As shown in Figure 5, five fundamental stages of the LOD can be differentiated in our model: LOD 100, LOD 200, LOD 300, LOD 400 and LOD 500.

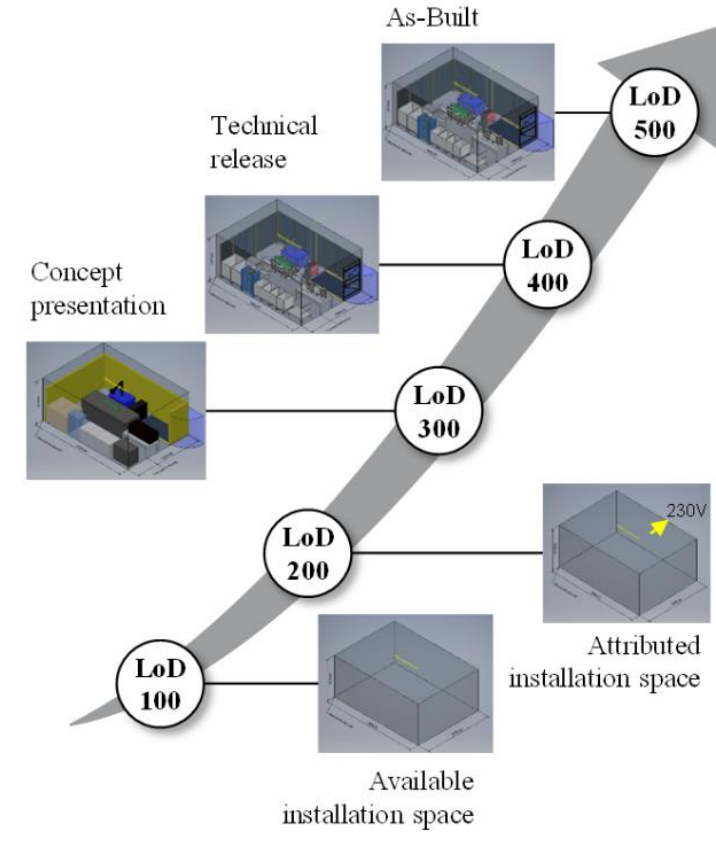

Figure 5. Stages of the LOD

For LOD 100 of the factory design process, the available installation space of potential production equipment should be defined and displayed. The elements do not have to be precisely modelled, but should rather be represented graphically with a symbol or a generic representation and information regarding the model element, such as the costs per square metre and the approximated available installation space. The $\operatorname{MEP}(\mathrm{H})$ designer at this stage would already begin to reserve space for some aggregates but without any relation to the production equipment yet.

Afterwards, this information should be expanded for LOD 200 where a first step towards non-geometrical information is taken. A first list of basic attributes of both production and $\operatorname{MEP}(\mathrm{H})$ equipment is generated, such as the required media connections (e.g. electricity, pressurised air, coolant) or the weight of the objects in order to gradually develop a parameterised construction/installation space. As for the LOG, objects are edited in a way that the graphical representation allows conclusions to the approximate size, shape, position and orientation of the components. These elements in LOD 200 can often be regarded as generic placeholders.

For LOD 300, the factory is visualised in the form of a concept presentation. The relevant information for closing contracts with suppliers should now be integrated into the model. LOD 300 therefore already requires a high LOI within the model's objects such as the transport direction of raw materials and products or the exact position and dimensioning of media connections, such as power supply connections or waste water pipes. Beyond the LOI, the LOG is also refined enabling direct measurement of the model elements based on a defined origin in the coordinate system.

Based on the information generated until reaching LOD 400 the technical release should be given and a detailed 3D model would be generated by the suppliers of both production and $\operatorname{MEP}(\mathrm{H})$ equipment. All necessary non-geometrical information must then be included in the model to ensure a clear technical inspection of the whole factory. For instance, this includes a final check of the demand for pressurised air for all machines and its comparison to the actual compressor from the $\operatorname{MEP}(\mathrm{H})$ supplier, considering simultaneity factors in 
operation, Bernoulli-related pressure losses and pipe dimensions.

The last stage, LOD 500 shows what is usually referred to by the term "as-planned" building, whereas some of the LOD 500-elements are developed in the As-Built stage.

This extended, factory-specific version of the LOD structure indicates in which way BIM design process specifications should be refined. This concrete solution recommendation should, in a next step, be expanded to other areas of factory design.

It has been emphasised that an integrated design of a factory can only be conducted efficiently if the right information in the right granularity is delivered to the correct design discipline at the right point in time within the design process. The above introduction of factory design specific LODs is a way to improve the quality of these information exchanges. This raises the question of how such an LOD system can be implemented in practice and framed by a certain standard. In this context, the Information Delivery Manual (IDM) by buildingSMART offers a possible framework for an implementation [35], which will be used in the course of our concrete solution recommendations.

It is the experts' opinion that the integration of our LODs into a standardised process model would enable unobstructed access to the exact information needed, and typical problems of information exchange (e.g. outdated information) could be counteracted. BuildingSMART's IDM, inter alia, consists of exchange requirements that allow to fundamentally describe the scope and specifications of an information that is required by a particular designer at a particular point in time in the design process. In addition, these requirements also regulate the time aspect of data exchange in accordance with the LODs. This time factor (also known as the fourth dimension of BIM - BIM4D) is of major importance in order to ensure timeliness and to avoid delays in the overall process, which are often a problem in today's BIM practice.

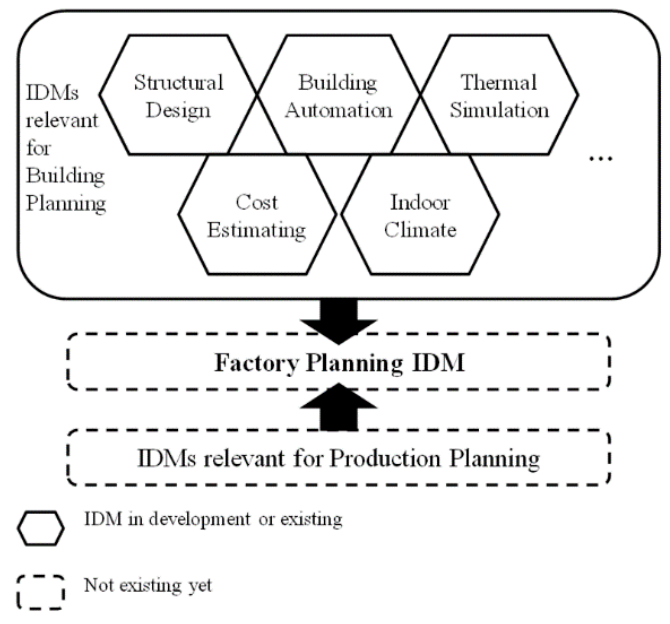

Figure 6. Missing factory design \& production design IDMs [36]

The goal of an IDM is therefore the standardisation of information needed for specific tasks within the design of a building. As shown in Figure 6, there already exists a high number of IDMs for building design. However, such IDMs do not yet exist for production design. Since factory design is the fusion of building design and production design it follows that there is no factory design IDM either. Accordingly, IDMs must first be developed for production design in order to combine them with building-related IDMs for the design of a factory design IDM [36].

The widespread implementation of such information exchange requirements including the above-mentioned LODs are seen as a first step towards improving the exchange of factory design information.

Such a standardised model with integrated information exchange requirements and cross-work availability could specify exactly which LOD is needed at which point of the factory design process by which other design disciplines. In this context, both the IDM exchange requirements and the IDM process map can be formulated based on the Aachen factory planning approach, but must be broken down onto parameter and attribute level [34, 37].

\section{IMPLEMENTATION AND CONCLUSION}

The study's objective was to develop concrete solution recommendations to facilitate BIM-based factory design within the interface of $\operatorname{MEP}(\mathrm{H})$ and production/process, explicitly targeting the efficient validation of design deliveries As results of our expert study, we have developed two concrete solution recommendations:

- Using ontologies to establish a knowledge engineering framework for the interface of production process design and $\mathrm{MEP}(\mathrm{H})$ and to enable automatic open-source design validations

- The development of specific standards for the factory design process (LOD and IDM)

To synthesise the concrete solution recommendations and make them graspable in the sense of real applicability, we have developed a process how both concrete solution recommendations could be integrated into a coherent process (see Figure 7).

The first thing to do is to establish a domain ontology for the interface $\operatorname{MEP}(\mathrm{H})$ and production (a). The experts suggested using the open-source software Protégé for it from Stanford university [38]. This ontology for the interface between production design and $\operatorname{MEP}(\mathrm{H})$ design is to be seen as the generally valid, project-independent truth of how objects, classes and attributes are related to each other within that interface (see Figure 8 without attributes).

When carrying out a specific project, the next step we defined is to use that generally valid ontology and transform it into a project-specific ontology by adding project-specific instances (e.g. numbers or other characteristics) to the classes and attributes of the ontology. Those instances are to be directly delivered from the different designers. Depending on the design discipline, there are a lot of different design and planning tools used for BIM-based factory design, such as Autodesk Revit, Autodesk Inventor or Nemetzschek Allplan. While they all primarily support their own proprietary file formats, they all are able to export $\operatorname{MEP}(\mathrm{H})$ information and production information from the Building Information Model in an Excel-format (b). Due to the object-oriented way of modelling in BIM, the attributes and their characteristics are therein transparently allocated to the object they pertain to. In the course of our expert study, we have also compared this approach with exporting the information in an IFC-format. But the effort to adjust the settings within the proprietary software in a way that no model information is lost became a major challenge and proved to be much less efficient than with the Excel-workaround. 


\section{a) Interface ontology}

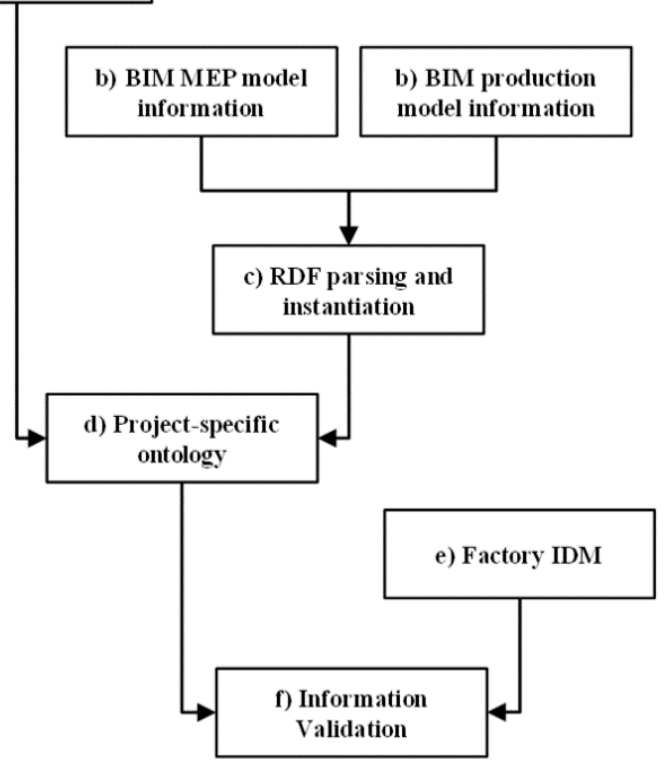

Figure 7. Process for validating BIM information with ontologies

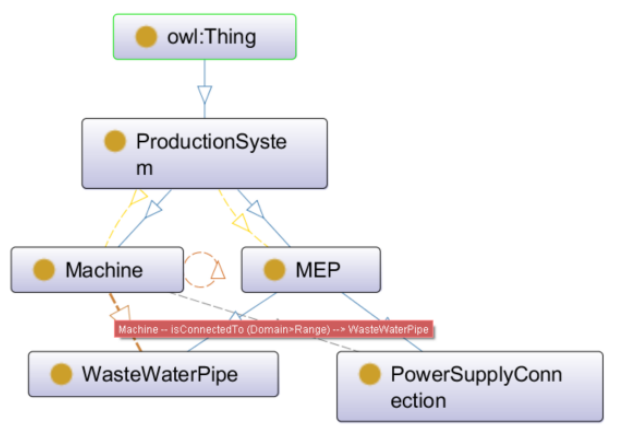

Figure 8. Ontology example in Protégé

Excel import

\begin{tabular}{|l|l|l|l|}
\hline Machine & $\begin{array}{l}\text { Power } \\
\text { Demand } \\
{[\mathbf{W}]}\end{array}$ & $\begin{array}{l}\text { Weight } \\
{[\mathbf{k g}]}\end{array}$ & $\begin{array}{l}\text { Size } \\
{\left[\mathbf{m}^{3}\right]}\end{array}$ \\
\hline $\begin{array}{l}\text { Milling machine } \\
\text { A11 }\end{array}$ & 19000 & 600 & 20 \\
\hline $\begin{array}{l}\text { Turning machine } \\
\text { A552 }\end{array}$ & 12000 & 900 & 30 \\
\hline
\end{tabular}

\section{Transformation Rule}

$\{$ "Collections":[\{"sheetName":"Process Infos", "startColumn":"A", "endColumn":"A", "startRow":"2", "endRow":"+", "comment":"'", "rule":"Individual: @A*

$$
\begin{aligned}
& \text { Types: Machine } \\
& \text { Facts: hasPowerDemand @B* } \\
& \text { (xsd:decimal), } \\
& \text { hasWeight@C* } \\
& \text { (xsd:integer } \\
& \text { mm: capturing }(\cap "([0- \\
& \text { 9]+) }(7) \text { )", "active" :ture\}, }
\end{aligned}
$$

\{"sheetName"::"Machine view", "startColumn":"A", "endColumn":"A",

"startRow":"2", "endRow":"+",, "comment":"',,"1ule":"Class: @A*

Figure 9. Extract of the Excel import spreadsheet \& transformation rules for ontology axiom creation
As the Web Ontology Language (OWL) is based on a special data model (the Resource Description Framework (RDF)) [39], the Excel information has to be parsed into the triple syntax format needed by RDF (Subject-Predicate-Object: Workpiece1 (Subject) is Processed By (Predicate) Machine2 $($ Object $)$ ). We wrote a simple conversion tool in JSON with Manchester Syntax in order to allocate the information from the Excel spreadsheets to the according classes and attributes within the ontology (c). This process is also called instantiation (see Figure 9). After having added that projectspecific information to the ontology, the generally valid ontology is transformed into the project-specific ontology (d) (see Figure 10).

This data delivered by the different design disciplines can then be validated against priorly formulated rules as stated in the second concrete solution recommendation (see section 3 ), as for example based on the IDM and its LODs including the exchange requirements (e). For this, we used Shapes Constraint Language (SHACL) to write a specific rule script (f) (see Figure 11). SHACL is specifically designed to validate RDF graphs (which our ontology is) against a set of conditions [40].

If the checked information does not cause any contradiction, the SHACL processor returns "sh: conforms: true". If the verification determines that a requirement or rule has been violated, this non-conformity is also reported. The SHACL processor returns a validation report that contains the occurred errors. Afterwards, the detected violations of the rules and requirements can be eliminated in order to ensure a successful design process.

The depicted process brings together the two expert solution recommendations from section 3 into one operable concept, allowing for a validation of design information independent of the individual proprietary design software.

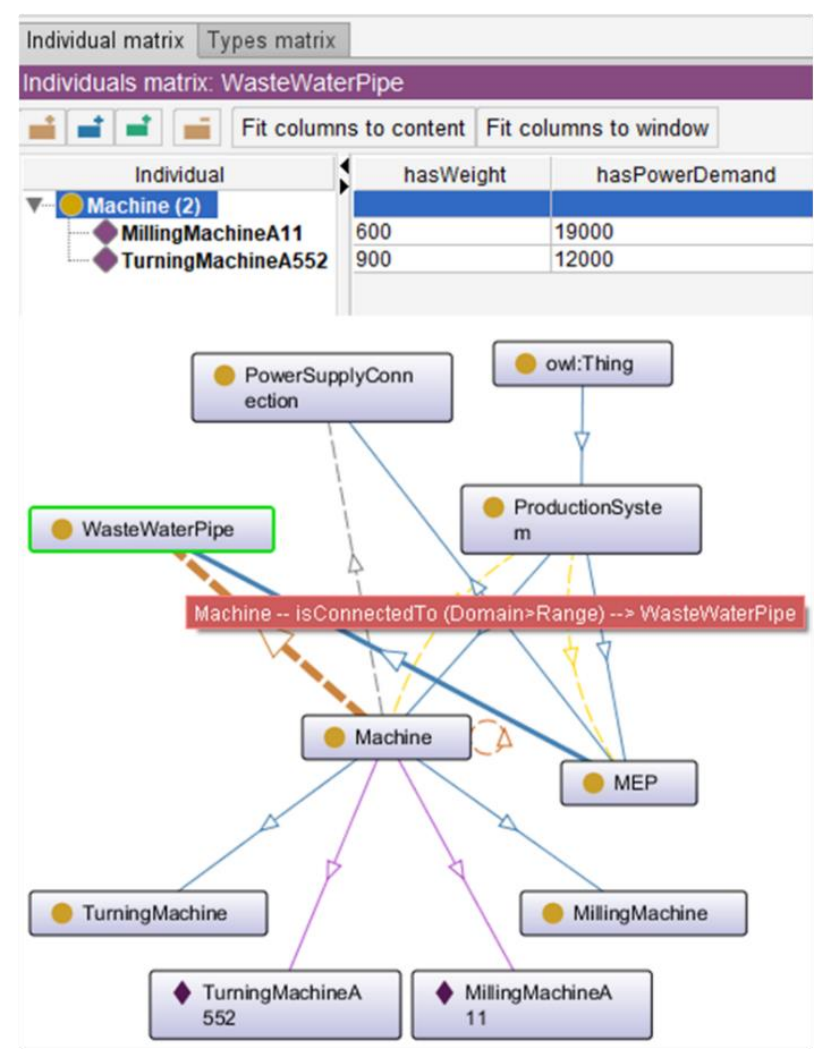

Figure 10. Project-specific ontology after insertion of project characteristics 
aprefix rdf: <http://www.w3.org/1999/02/22-rdf-syntax-ns\#> .

a prefix sh: <http://www.w3.org/ns/shacl\#>

a prefix xsd: <http://www.w3.org/2001/XMLSchema\#>

a prefix rdfs: <http://www.w3.org/2000/01/rdf-schema\#>

a prefix ex: <http://www.example.org/\#>

aprefix owl: <http://www.w3.org/2002/07/owl\#>

ex:MachineShape

a sh:NodeShape ;

sh:targetClass ex:Machine ; \# Applies to all machines

sh:property [ \# :b0

sh:path ex:PowerDemand ; \# constrains the values of ex:PowerDemand

sh:maxCount 1 ; ];

Figure 11. Extract of the rule script in SHACL

In a further research step, databases and underlying SQLqueries (Structured Query Language) could also be tested to fulfil the requirements of the BIM-based factory design process. However, ontologies prove to be advantageous due to their open-source nature, their general, project-independent validity, their extensibility and their possibility to be re-used in other ontologies, as is the main idea of the Semantic Web. Yet, Protégé as the main software for ontologies is not intuitive and may incur hesitations to designers and BIM managers.

On the geometrical side, already existing 3D model libraries should be included in further research although particular attention has to be paid to non-geometrical, process-related information which those objects often lack.

With the rising complexity of building projects [41], a building's design will need to integrate an increasing number of designers and their according design information. We have shown the relevance of this phenomenon in the special field of factory design. In such complex projects, the integrity of building information and building data is of utmost importance. The ability to automatically check design information delivered by different designers can significantly reduce errors in cross-work collaboration in BIM and thereby reach a new level of BIM-based design. Ontologies offer a method where the dependencies and logical relationships within design interfaces can be transparently displayed and used for automatic validation of the project-specific information. While we acknowledge that it is not intuitive and user-friendly to work with ontologies, we are convinced by the benefits as an open-source, transparent knowledge engineering method to ensure a non-proprietary validation technique for all design disciplines in BIM.

\section{REFERENCES}

[1] Burggräf, P., Ebade Esfahani, M., Bertling, M., Dannapfel, M. (2018). Factory-BIM zur integrierten Produktions- und Gebäudeplanung. VPP2018 - Vernetzt planen und produzieren, Chemnitz, pp. 155-166.

[2] Ademmer, M., Bickenbach, F., Bode, E., BoysenHogrefe, J., Fiedler, S., Gern, K.J., Görg, H., Groll, D., Hornok, C., Jannsen, N., Kooths, S., Krieger-Boden, C. (2017). Produktivität in Deutschland: Messbarkeit und Entwicklung, p. 2. http://hdl.handle.net/10419/172261, accessed on 26 August 2020.

[3] Gesellschaft zur Digitalisierung des Planens. planen- bauen 4.0. https://planen-bauen40.de, accessed on 26 August 2020.

[4] Federal Ministry of Transport and Digital Infrastructure (2015). Road Map for Digital Design and Construction, p. 3.

[5] Verordnung über die Honorare für Architekten- und Ingenieurleistungen (Honorarordnung für Architekten und Ingenieure - HOAI), 2013.

[6] Verein Deutscher Ingenieure VDI-Richtlinie 5200: Factory planning, Planning procedures. https://standards.globalspec.com/std/1298150/VDI\%20 5200\%20BLATT\%201, accessed on 26 August 2020.

[7] Näser, P., Wickenhagen, N. (2018). Fabrik-Integration in das Building Information Modeling (BIM). wt Werkstattstechnik online, 108(4). https://e-paper.vdifachmedien.de/webreader-v3/index.html\#/2091/49, accessed on 26 August 2020.

[8] Ladiana, D., Di Sivo, M. (2019). Programmed conservation of historical and architectural heritage. Tools for optimising a process based on knowledge and information. International Journal of Design \& Nature and Ecodynamics, 14(3): 229-240. https://doi.org/10.2495/DNE-V14-N3-229-240

[9] Bund Deutscher Architekten Bundesverband. (2011). Architects in Germany. pp. 1-2. https://www.bdabund.de/2011/09/architects-in-germany/, accessed on 26 August 2020.

[10] Burggräf, P., Dannapfel, M., Schneidermann, D., Ebade Esfahani, M., Schwamborn, N. (2019). Integrated factory modelling. BIM 2019, Seville, Spain. https://doi.org/10.2495/BIM190131

[11] Arayici, Y., Fernando, T., Munoz, V., Bassanino, M. (2018). Interoperability specification development for integrated BIM use in performance based design. Automation in Construction, 85: 167-181. https://doi.org/10.1016/j.autcon.2017.10.018

[12] Hu, Z.Z., Tian, P.L., Li, S.W., Zhang, J.P. (2018). BIMbased integrated delivery technologies for intelligent MEP management in the operation and maintenance phase. Advances in Engineering Software, 115: 1-16. https://doi.org/10.1016/j.advengsoft.2017.08.007

[13] Lee, Y.C., Eastman, C.M., Solihin, W. (2016). An ontology-based approach for developing data exchange requirements and model views of building information modeling. Advanced Engineering Informatics, 30(3): 354-367. https://doi.org/10.1016/j.aei.2016.04.008

[14] Ma, Z., Zhang, D., Li, J. (2018). A dedicated collaboration platform for integrated project delivery. Automation in Construction, 86: 199-209. https://doi.org/10.1016/j.autcon.2017.10.024

[15] buildingSMART International. bSI Standards. https://www.buildingsmart.org/standards/bsi-standards/, accessed on 26 August 2020.

[16] vom Brocke, J., Simons, A., Niehaves, B., Reimer, K., Plattfaut, R., Cleven, A. (2009). Reconstructing the giant: On the importance of rigour in documenting the literature search process. ECIS 2009 Proceedings, Paper 161. Verona, Italy. https://aisel.aisnet.org/ecis2009/161/

[17] Meuser, M., Nagel, U. (2016). The Expert Interview and Changes in Knowledge Production. In: Bogner A., Littig B., Menz W. (eds) Interviewing Experts. Research Methods Series. Palgrave Macmillan, London. https://doi.org/10.1057/9780230244276_2

[18] Bortz, J., Döring, N. (2006). Forschungsmethoden und 
Evaluation: Springer-Lehrbuch Bachelor, Master. Springer-Medizin-Verl., Heidelberg.

[19] Mayring, P. (2010). Qualitative Inhaltsanalyse. In: Mey G., Mruck K. (eds) Handbuch Qualitative Forschung in der Psychologie. VS Verlag für Sozialwissenschaften. https://doi.org/10.1007/978-3-531-92052-8_42

[20] Hsieh, H.F., Shannon, S.E. (2005). Three approaches to qualitative content analysis. Qualitative Health Research, 15(9): $1277-1288$ https://doi.org/10.1177/1049732305276687

[21] Miles, M.B., Huberman, A.M. (2009). Qualitative Data Analysis. Sage, Thousand Oaks, Calif.

[22] Gronau, N. (2008). Wettbewerbsfähigkeit durch Arbeitsund Betriebsorganisation, Berlin: Gito-Verl.

[23] Zhang, J., El-Gohary, N. (2012). Extraction of construction regulatory requirements from textual documents using natural language processing techniques. International Conference on Computing in Civil Engineering, Clearwater Beach, Florida, United States. https://doi.org/10.1061/9780784412343.0057

[24] Zhang, J., El-Gohary, N.M. (2017). Integrating semantic NLP and logic reasoning into a unified system for fullyautomated code checking. Automation in Construction, 73: 45-57. https://doi.org/10.1016/j.autcon.2016.08.027

[25] Hjelseth, E., Nisbet, N. (2011). Capturing normative constraints by use of the semantic mark-up (RASE) methodology. Proceedings of the CIB W78-W102 2011: International Conference -Sophia Antipolis, France, pp $1-10$.

[26] Warren, D. (2019). Parametric modelling in construction: Investigating the quality of rule-based checking. WIT Transactions on The Built Environment, 192: 57-68. https://doi.org/10.2495/BIM190061

[27] Preidel, C., Borrmann, A. (2016). Towards code compliance checking on the basis of a visual programming language. Journal of Information Technology in Construction (ITcon), 21: 402-421.

[28] Kim, H., Lee, J.K., Shin, J., Choi, J. (2019). Visual language approach to representing KBimCode-based Korea building code sentences for automated rulechecking. Journal of Computational Design and Engineering, 6(2): 143-148. https://doi.org/10.1016/j.jcde.2018.08.002

[29] Pauwels, P., Terkaj, W. (2016). EXPRESS to OWL for construction industry: Towards a recommendable and usable ifcOWL ontology. Automation in Construction, 63 .

$100-133$. https://doi.org/10.1016/j.autcon.2015.12.003

[30] Budaev, D., Lada, A., Simonova, E., Skobelev, P., Travin, V., Yalovenko, O., Voshchuk, G., Zhilyaev, A. (2018). Conceptual design of smart farming solution for precise agriculture. International Journal of Design \& Nature and Ecodynamics, $\quad$ 13(3): 307-314. https://doi.org/10.2495/DNE-V13-N3-307-314

[31] Kuehn, W. (2018). Digital twins for decision making in complex production and logistic enterprises. International Journal of Design \& Nature and Ecodynamics, 13(3): 260-271. https://doi.org/10.2495/DNE-V13-N3-260-271

[32] BIMForum (2019). Level of Development (LOD) Specificatioin Part $1 \&$ \& Commentary. https://bimforum.agc.org/wpcontent/uploads/sites/27/2020/04/3.12.20-LOD-Spec2019-Part-I-and-Guide-2019-04-29.pdf, accessed on 26 August 2020.

[33] Schuh, G., Kampker, A., Wesch-Potente, C. (2011). Condition based factory planning. Production Engineering, 5(1): 89-94. https://doi.org/10.1007/s11740-010-0281-y

[34] Krunke, M. (2017). Maturity Management in Factory Planning. https://publications.rwthaachen.de/record/697755, accessed on 26 August 2020.

[35] buildingSMART International. Model View Definitions (MVD). https://www.buildingsmart.org/standards/bsistandards/model-view-definitions-mvd/, accessed on 26 August 2020.

[36] buildingSMART International. IDM Database. https://technical.buildingsmart.org/resources/informatio n-delivery-manual/idm-database/, accessed on 26 August 2020.

[37] Deutsches Institut für Normung e.V., DIN EN ISO 19650-1:2019-08. Organization and digitization of information about buildings and civil engineering works, including building information modelling (BIM) Information management using building information modelling- Part 1: Concepts and principles (ISO 196501:2018). Beuth-Verlag, Berlin, 2019. https://www.beuth.de/de/norm/din-en-iso-196501/299953244, accessed on 26 August 2020.

[38] Stanford university. Protégé. https://protege.stanford.edu/, accessed on 26 August 2020.

[39] Web Ontology Language (OWL). https://www.w3.org/OWL/, accessed on 26 August 2020.

[40] Shapes Constraint Language (SHACL). https://www.w3.org/TR/shacl/, accessed on 26 August 2020.

[41] White, B.E. (2016). On a maturity model for complexity, complex systems, and complex systems engineering. International Journal of Design \& Nature and Ecodynamics, 11(4): 532-542. https://doi.org/10.2495/DNE-V11-N4-532-542 